\title{
BITEMPLATE SYNTHESIS OF MESOPOROUS SILICAS WITH THIOUREA GROUPS
}

\author{
O. I. Gona ${ }^{a}$, N. V. Stolyarchuk ${ }^{a}$, Yu. L. Zub ${ }^{a}$, and N. A. Yaroshenko ${ }^{b}$ \\ ${ }^{a}$ O.O.Chuiko Institute of Surface Chemistry, National Academy of Sciences of Ukraine, \\ 17, General Naumov Str., Kyiv 03164 Ukraine \\ ${ }^{b}$ Institute of sorption and endoecology problems National Academy of Sciences of Ukraine, \\ 13, General Naumov Str., Kyiv 03164 Ukraine \\ *e-mail: zubyuriy@isc.gov.ua, tel: +38-044-422-9630 fax: +38-044-424-3567
}

\begin{abstract}
Mesoporous silicas with the thiourea functional group $\equiv \mathrm{Si}\left(\mathrm{CH}_{2}\right)_{3} \mathrm{NHC}(\mathrm{S}) \mathrm{NHC}_{2} \mathrm{H}_{5}$ have been synthesized by monotemplate and bitemplate route (bitemplate is cetylpyridinium chloride as micelle-forming surfactant and monoethanolamide of saturated $n$-aliphatic acid as non-micelle-forming surfactant). The influence of a number of factors on mesoporous silicas structure has been studied: alkoxysilanes and surfactants concentration, and as well as the nature of medium in hydrothermal treatment of mesophases. The optimum conditions under which functionalized mesoporous silicas have possessing highly ordered hexagonal structure have been found. The surface area of mesoporous silicas synthesized using optimum bitemplate solubilization composition reaches $1055-1350 \mathrm{~m}^{2} / \mathrm{g}$ and sorption volume and pore diameter are $0.75-0.95 \mathrm{~cm}^{3} / \mathrm{g}$ and $2.5-2.9 \mathrm{~nm}$ respectively.
\end{abstract}

Keywords: mesoporous silicas, bitemplate synthesis, thiourea functional group.

\section{Introduction}

Mesoporous silicas with complexing groups are usually obtained by modification of synthesized samples surface [1-5]. More promising alternative is the introduction of functional groups directly during template synthesis. It conducts to reduction of the number of synthesis steps. Besides, it gives the opportunity to introduce different functional groups (at desired ratios) into the silica surface layer simultaneously. Earlier, the papers [6-16] have already shown the possibility of production of functionalized mesoporous silicas which were obtained in the one-pot template synthesis by using tetraalkoxysilanes, trifunctional silanes and various surfactants such as 1-dodecylamine, cetyltrimethylammonium bromide, and triblock polymers. However, in many cases after template extraction the final products had a less-ordered spatial structure and a relatively low specific surface area $[8,17,18]$. It is worth mentioning about the effect of bitemplate solubilization composition on the perfection degree of a spacial structure of mesoporous silicas [19]. Therefore, in this work bitemplate synthesis method was used for the production of functionalized mesoporous silicas. As a bitemplate the solubilization composition generated by mixed solubilization type has been used: the solubilizer was efficient micelleforming surfactant (cetylpyridinium chloride, $\mathrm{C}_{16} \mathrm{PyCl}$ ) and the solubilizate was slightly soluble in water non-micelleforming surfactant (monoethanolamide of saturated $n$-aliphatic acid with hydrocarbon radical length $\mathrm{C}_{12}\left(\mathrm{EAC}_{12}\right)$ and $\mathrm{C}_{14}\left(\mathrm{EAC}_{14}\right)$ ). In contrast to [19] where the source of silicon dioxide was sodium metasilicate, tetraethoxysilane was used in this work. As a trifunctional silane was used $\left(\mathrm{C}_{2} \mathrm{H}_{5} \mathrm{O}\right)_{3} \mathrm{Si}_{2}\left(\mathrm{CH}_{2}\right)_{3} \mathrm{NHC}(\mathrm{S}) \mathrm{NHC}_{2} \mathrm{H}_{5}$ (ETUS) enabling to embed into surface layer such complexing group as the thiourea which is important from practical point of view. The appearance of such group in the surface layer of mesoporous silicas enables to utilize them as highly efficient and selective sorbents of heavy and noble metals [20].

\section{Experimental}

As initial materials were used: tetraethoxysilane, $\mathrm{Si}\left(\mathrm{OC}_{2} \mathrm{H}_{5}\right)_{4}$ (TEOS, 98\%); cetylpyridinium chloride $\left[\mathrm{CH}_{3}\left(\mathrm{CH}_{2}\right)_{15} \mathrm{~N}\left(\mathrm{C}_{5} \mathrm{H}_{5}\right)\right] \mathrm{Cl}$ (99.9\%); ethanol; $25 \%$ solution $\mathrm{NH}_{4} \mathrm{OH}$ (all reagents "Aldrich"). Monoethanolamides of saturated $n$-aliphatic acid $\left(\mathrm{EAC}_{\mathrm{m}}\right)$ with $m$ carbon atoms 12 and 14 were prepared by the known procedure [21] using reaction of methyl esters of alkylcarboxylic acids with monoethanolamine $\mathrm{RC}(\mathrm{O}) \mathrm{OCH}_{3}+\mathrm{H}_{2} \mathrm{NC}_{2} \mathrm{H}_{4} \mathrm{OH} \rightarrow \mathrm{RC}(\mathrm{O})$ $\mathrm{NHC}_{2} \mathrm{H}_{4} \mathrm{OH}+\mathrm{CH}_{3} \mathrm{OH}$. For bitemplate synthesis the solubilization solution has been prepared as a preliminary using certain concentrations of the solubilizer $\left(\mathrm{C}_{16} \mathrm{PyCl}\right)$ and the solubilizate $\left(\mathrm{EAC}_{12}\right.$ or $\left.\mathrm{EAC}_{14}\right)$. The trifunctional silane with thiourea groups - $\left(\mathrm{C}_{2} \mathrm{H}_{5} \mathrm{O}\right)_{3} \mathrm{Si}\left(\mathrm{CH}_{2}\right)_{3} \mathrm{NHC}(\mathrm{S}) \mathrm{NHC}_{2} \mathrm{H}_{5}$, ETUS - was synthesized according to [22]. 0.01M solution $\mathrm{HCl}$ in etanol was prepared by adding to $96 \%$ etanol of the calculated amount of concentrated hydrochloric acid.

The synthesis of organosilica samples was carried out using the following method. In the case of FMS-1 (TEOS/ ETUS $=10: 1)$ to the solution 0.00885 mole $\mathrm{C}_{16} \mathrm{PyCl}$ in water $\left(175 \mathrm{~cm}^{3}\right)$ at stirring were added 0.0019 mole ETUS dissolved in ethanol $\left(130 \mathrm{~cm}^{3}\right)$, then 0.019 mole TEOS. After $10 \mathrm{~min}$. of constant stirring, $57.8 \mathrm{~cm}^{3}$ of $\mathrm{NH}_{4} \mathrm{OH}$ was added drop by drop. Approximately in two minutes from a clear solution the precipitation dropped out. It was to stand at ambient temperature for $48 \mathrm{~h}$. The resulting white precipitate was exposed to hydrothermal treatment (HTT) at $80 \pm 2^{\circ} \mathrm{C}$ for $24 \mathrm{~h}$. Then the solid sample was filtered and dried in air for $48 \mathrm{~h}$. The surfactant was extracted from obtained white powder material by help of $0.01 \mathrm{M} \mathrm{HCl}$ solution in ethanol which was boiled for $3 \mathrm{~h}$ (at the rate of $45 \mathrm{~cm}^{3}$ of solvent and 
$1 \mathrm{~g}$ of sample). The operation was repeated three times and after that the sample was dried in vacuum at $110^{\circ} \mathrm{C}$ for $4 \mathrm{~h}$. The sample denoted as FMS-2M (TEOS/ETUS = 5:1) was synthesized in the similr way.

In the case of FMS-3 $\left(\mathrm{C}_{16} \mathrm{PyCl} /(\mathrm{TEOS}+\mathrm{ETUS})=1: 2.36\right)$ the stirring of the suspension was sustained for 2 hours and then it was kept at ambient temperature for 2 days. The white precipitate was exposed to $\mathrm{HTT}$ at $80 \pm 2^{\circ} \mathrm{C}$ for 3 days in mother liquor $(\mathbf{M})$ or in water $(\mathbf{H})$. Then it was filtered and dried in air for $48 \mathrm{~h}$. The surfactant was extracted as mentioned above. The samples FMS-4M and FMS-4H were synthesized in the same way, but $\mathrm{C}_{16} \mathrm{PyCl}_{\text {(TEOS+ETUS) }}$ $=1: 4$.

The bitemplate synthesis of samples was carried out analogous using the solubilization composition of $\mathrm{C}_{16} \mathrm{PyCl}$ and $\mathrm{EAC}_{\mathrm{m}}$. The solubility of $\mathrm{EAC}_{\mathrm{m}}$ in water at $20^{\circ} \mathrm{C}$ is $9 \mathrm{mg} / \mathrm{l}($ for $\mathrm{m}=12)$ and $2 \mathrm{mg} / \mathrm{l}($ for $\mathrm{m}=14)$. The conditions of

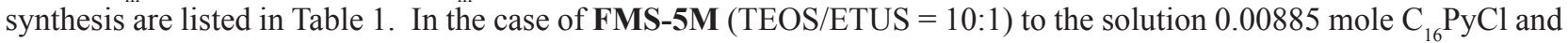
0.000885 mole $\mathrm{EAC}_{12}\left(80 \mathrm{~cm}^{3}\right.$ of ethanol and $175 \mathrm{~cm}^{3}$ of water $)$ at stirring were added 0.0019 mole ETUS dissolved in ethanol $\left(50 \mathrm{~cm}^{3}\right)$, then 0.019 mole TEOS. After $10 \mathrm{~min}$. of constant stirring, $57.8 \mathrm{~cm}^{3}$ of $\mathrm{NH}_{4} \mathrm{OH}$ was added drop by drop. In two minutes from a clear solution the precipitation dropped out. The stirring of the suspension was sustained for 2 hours and then it was kept at ambient temperature for 3-4 days without stirring. The white precipitate was exposed to HTT at $80 \pm 2^{\circ} \mathrm{C}$ for $72 \mathrm{~h}$. Then it was filtered and dried in air for $48 \mathrm{~h}$. The surfactant was extracted from obtained white powder material by help of $0.01 \mathrm{M} \mathrm{HCl}$ solution in ethanol which was boiled for $3 \mathrm{~h}$ (at the rate of $45 \mathrm{~cm}^{3}$ of solvent and $1 \mathrm{~g}$ of sample). The operation was repeated three times and after that the sample was dried in vacuum at $110^{\circ} \mathrm{C}$ for $4 \mathrm{~h}$.

The elemental analysis was performed in Analytical Laboratory of the Institute of Organic Chemistry (NASU, Kyiv). The X-Ray diffraction powder patterns were collected on a DRON-4-07 diffractometer $\left(\mathrm{Cu}_{\mathrm{K} \alpha}-\mathrm{radiation}^{-}\right.$. The DRIFT spectra were recorded on the Thermo Nicolet Nexus FT-IR in the region of $4000-400 \mathrm{~cm}^{-1}$ at $8 \mathrm{~cm}^{-1}$ resolution by using the Spectra Tech collector diffuse reflectance accessory at room temperature. The samples were mixed up with $\mathrm{KBr}(1: 30)$, and that mixture was used to fill the DRIFT sample cup before measurements.

SEM photomicrographs of samples were obtained with a Tesla BS301 scanning electron microscope. TEM image was obtained on a JEM 2010 microscope operating at $200 \mathrm{kV}$ for which the sample was dispersed in ethanol by supersonic treatment and then the drop was deposited on a grid with a holey carbon film.

The nitrogen adsorption isotherms were measured by the "Kelvin-1042" adsorption analyzer. Before the measurements, the samples were outgassed at $383 \mathrm{~K}$ in the helium atmosphere for $2 \mathrm{~h}$. The BET specific surface area [23] was calculated in the range of relative pressure range between 0.05 and 0.35 . The total volume of pore $\left(\mathrm{V}_{\mathrm{s}}\right)$ was determined from the amount of nitrogen which was adsorbed at the relative pressure of 0.99 [23]. The pore size distributions were determined by using the Barrett, Joyner and Halenda (BJH) approach [24].

\section{Results and discussion}

The preparation of mesoporous silicas which contained $\equiv \mathrm{Si}\left(\mathrm{CH}_{2}\right)_{3} \mathrm{NHC}(\mathrm{S}) \mathrm{NHC}_{2} \mathrm{H}_{5}$ functional groups in the surface layer was carried out by using of the traditional template method $[19,25,26]$. During synthesis the following conditions have been varied (Table 1): alkoxysilanes concentration, the carbon chain length in solubilizate (EAC ${ }_{m}$, $m=12$ or 14), its concentration and the medium, where HNN was performed - mother solution (FMS-M samples) or

Structural and structural-adsorption characteristics of functionalized mesoporous silicas

Table 1

\begin{tabular}{|c|c|c|c|c|c|c|c|c|c|}
\hline \multirow[b]{2}{*}{ Sample } & \multirow[b]{2}{*}{$\begin{array}{c}\text { Molar Ratio } \\
\text { of Reaction Mixture }\end{array}$} & \multicolumn{2}{|c|}{ Initial Form } & \multicolumn{3}{|c|}{ Removed Form } & \multirow[t]{2}{*}{$\mathrm{S}_{\mathrm{sp},} \mathrm{m}^{2} / \mathrm{g}$} & \multirow[t]{2}{*}{$\mathrm{V}_{\mathrm{s}}, \mathrm{cm}^{3} / \mathrm{g}$} & \multirow[t]{2}{*}{$\mathrm{d}, \mathrm{nm}$} \\
\hline & & $d_{100}, \mathrm{~nm}$ & $\mathrm{a}_{0}, \mathrm{~nm}$ & $d_{100}, \mathrm{~nm}$ & $\mathrm{a}_{0}, \mathrm{~nm}$ & $\begin{array}{c}\mathrm{I}^{\mathrm{a}}, \mathrm{sec}^{-1} \\
\text { (a.u.) }\end{array}$ & & & \\
\hline \multicolumn{10}{|c|}{$\mathrm{C}_{16} \mathrm{PyCl} / \mathrm{TEOS} / \mathrm{ETUS}$ (Monotemplate Systems) } \\
\hline FMS-1M & $1 / 2.15 / 0.21$ & 3.65 & 4.22 & 3.67 & 4.23 & 12880 & 1132 & 0.62 & 2.5 \\
\hline FMS-2M & $1 / 2.15 / 0.43$ & 3.67 & 4.23 & 3.53 & 4.08 & 18500 & 1172 & 0.60 & 2.9 \\
\hline FMS-3M & $1 / 2.15 / 0.21$ & 3.76 & 4.34 & 3.93 & 4.53 & 24240 & 1058 & 0.66 & 2.5 \\
\hline FMS-3H & $1 / 2.15 / 0.21$ & 3.76 & 4.34 & 3.76 & 4.34 & 24090 & 1132 & 0.87 & 2.5 \\
\hline FMS-4M & $1 / 3.64 / 0.36$ & 3.84 & 4.44 & 3.84 & 4.44 & 23960 & 1372 & 0.79 & 2.5 \\
\hline FMS-4H & $1 / 3.64 / 0.36$ & 3.84 & 4.44 & 3.93 & 4.53 & 22420 & 1064 & 0.62 & 2.5 \\
\hline \multicolumn{10}{|c|}{$\mathrm{C}_{16} \mathrm{PyCl} / \mathrm{EAC}_{\mathrm{m}} / \mathrm{TEOS} / \mathrm{ETUS}$ (Bitemplate Systems) } \\
\hline FMS-5M & $1 / 0.10 / 2.15 / 0.21$ & 3.76 & 4.34 & 3.84 & 4.44 & 27020 & 1045 & 0.60 & 2.5 \\
\hline FMS-5.1M & $1 / 0.15 / 2.15 / 0.21$ & - & - & 3.68 & 4.25 & 17100 & - & - & - \\
\hline FMS-5.2M & $1 / 0.33 / 3.62 / 0.36$ & 3.68 & 4.25 & 3.84 & 4.44 & 9100 & 1036 & 0.66 & 2.5 \\
\hline FMS-5.2H & $1 / 0.33 / 3.62 / 0.36$ & 3.68 & 4.25 & 4.02 & 4.64 & 9410 & - & - & - \\
\hline FMS-6M & $1 / 0.05 / 2.15 / 0.21$ & 3.84 & 4.44 & 3.84 & 4.44 & 27690 & 1352 & 0.75 & 2.5 \\
\hline FMS-6H & $1 / 0.05 / 2.15 / 0.21$ & 3.84 & 4.44 & 4.02 & 4.64 & 23980 & 1055 & 0.95 & 2.9 \\
\hline
\end{tabular}




\begin{tabular}{|l|r|l|l|l|l|r|r|r|c|}
\hline FMS-6.1H & $1 / 0.14 / 3.64 / 0.36$ & 3.68 & 4.25 & 3.93 & 4.53 & 9710 & - & - & - \\
\hline FMS-6.2H & $1 / 0.14 / 3.64 / 0.72$ & 3.84 & 4.44 & 3.84 & 4.44 & 15280 & - & - & - \\
\hline
\end{tabular}

${ }^{\mathrm{a}}$ Intensity of the first reflex in X-ray diffraction pattern.

water (FMS-H samples). The obtained powder samples, as shown in Fig. 1, represent the aggregates of practical spherical particles with the size of about $0.5 \mu \mathrm{m}$. The data of element analysis, which was performed for nitrogen and sulfur, shows that the content of functional groups in the synthesized samples has been closed to $1.2 \mathrm{mmol} / \mathrm{g}$ (if TEOS/ ETMS ratio (mol.) in the initial solution was 10:1 and when it was closed to $1.8 \mathrm{mmol} / \mathrm{g}$ (if that ratio was 10:2).
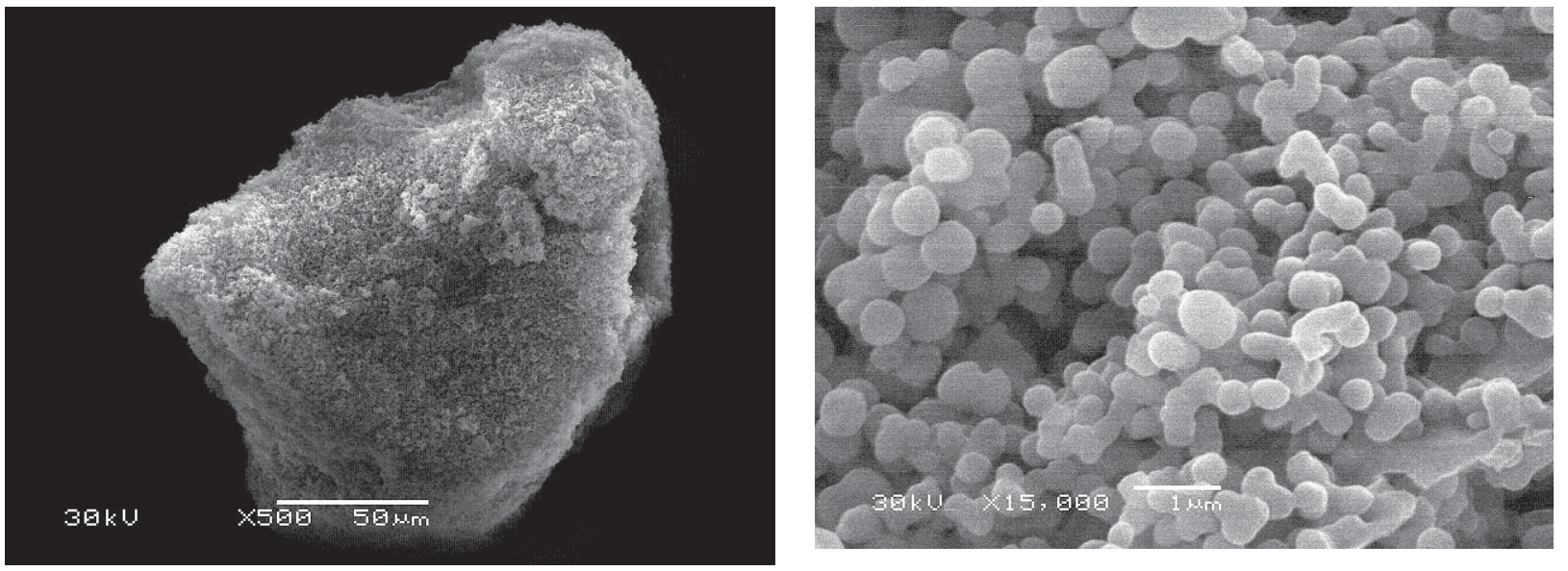

Figure 1. Micrographs of FMS-1M sample obtained by SEM.

The IR spectra of the initial trifunctional silane with thiourea group, cetylpyridinium chloride, monoethanolamides and the samples denoted as FMS-5M, FMS-6M and FMS-6H are shown in Fig. 2. The IR spectra of other mesoporous silicas that were obtained after template extraction are identical. All of them have the most intensive absorption band with high frequency shoulder in the region of 1050-1200 $\mathrm{cm}^{-1}$. Its appearance can be attributed to formation of the three-dimensional siloxane framework which contains the carbofunctional groups [27]. Also the IR spectra of all samples has a sharp medium-intensity absorption band about $1560 \mathrm{~cm}^{-1}$, which can be attributed to $v_{\text {as }}(\mathrm{NCN})$ vibration of the thiourea fragment $-\mathrm{NH}-\mathrm{C}(\mathrm{S})-\mathrm{NH}-$ [28]. This fact is also confirmed by the existence of an intensive and broad absorption band $v(\mathrm{NH})$ about $3300 \mathrm{~cm}^{-1}$, which is typical of initial ETUS (Fig. 2). Possibly this band is overlapped by another one - the absorption band of $v(\mathrm{OH})$ vibration of water, since IR spectra of all the obtained samples contains a small-intensity absorption band at $\sim 1630 \mathrm{~cm}^{-1}$, which may be ascribed to $\delta\left(\mathrm{H}_{2} \mathrm{O}\right)$. Furthermore, in the region of $2800-3000 \mathrm{~cm}^{-1}$ one can identify well-defined absorption bands of valence vibrations of alkyl radicals $\mathrm{C}-\mathrm{H}$ bonds, but absorption bands which are typical to such templates, are not present in the IR spectra (Fig. 2). Therefore, one can assume that during HTT and extraction the practically full removal of templating agents from mesophases takes place and the sulfur-containing functional groups destruction does not take place in the surface layer. The similar situation has also been observed for mesoporous silicas with thiourea group that were obtained by using $\mathrm{C}_{16} \mathrm{PyCl}$ only [29]. However, in this case, in accordance with the data of ${ }^{13} \mathrm{C} \mathrm{CP} / \mathrm{MAS}$ NMR spectroscopy, the samples contain insignificant amount of template.

The X-ray diffraction patterns of synthesized samples usually have 3-4 reflexes in the region of small angles (Fig. 3 ), that testifies to formation of MCM-41-type spatial structure. This statement is confirmed by micrographs of these samples that are obtained by TEM (Fig. 4) - they contain clearly formed regions with hexagonally ordered structure.

The preliminary investigation was shown while performing HTT, independently from the medium - was it water or mother liquor - the relative intensity of all of the reflexes slightly increased and at the same time the first reflex narrowed a little bit. Therefore, HTT allows to obtain samples with more ordered structure. One can see the same effect at the time of HTT's increase from 1 to 3 days (Table 1, FMS-1M and FMS-3M samples accordingly). This follows from the final estimate of structural characteristics of samples, which were emanated from their X-ray diffraction patterns (Fig. 3), where the main attention was paid not to the increase of the first reflex intensity, but to the increase of all further reflexes' intensity, their number, resolution and symmetry. Therefore, HTT for the rest of samples was 3 days. 


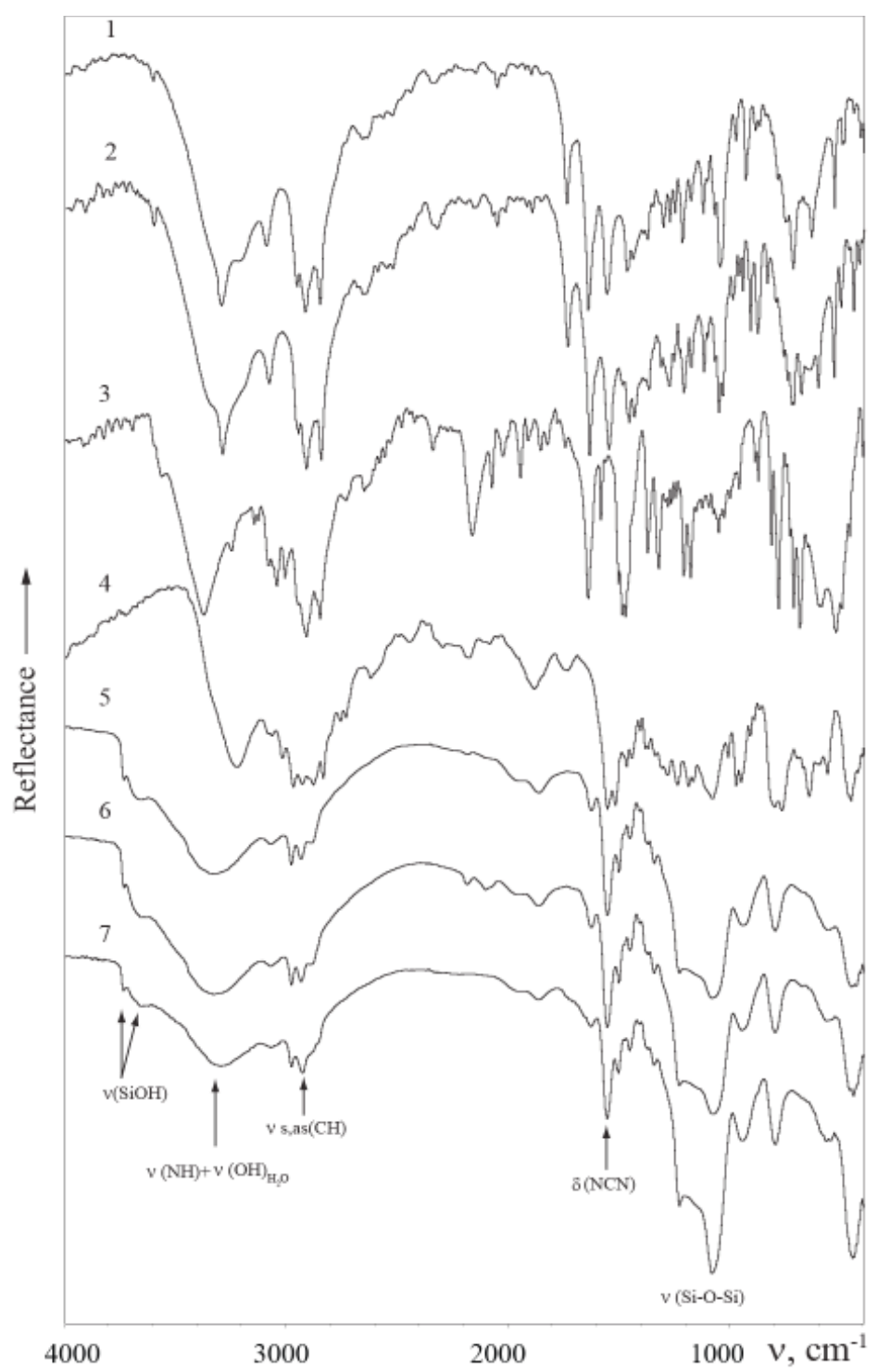

Figure 2. IR spectra of initial reagents: $\operatorname{EAC}_{12}(1), \mathrm{EAC}_{14}(2), \mathrm{C}_{16} \mathrm{PyCl}(3)$, ETMS (4) and resulting samples: FMS-5M, FMS-6M и FMS-6H (5, 6 and 7 respectively).

The comparison of X-ray diffraction patterns (Fig. 3) for samples that were syntezied using monotemplate variant with those which were obtained by application of bitemplate variant demonstrates, that the usage of template solubilization composition of combined type raises the perfection degree of spatial structure of the final functionalized material. The effect of bitemplate solubilization composition evinces in the formation of more perfect spatial mesophases on the initial stage of synthesis. This effect is likely connected with an increase in strength, density, and rigidity of micelles which is due to interaction between $\mathrm{C}_{16} \mathrm{PyCl}$ and solubilized monoethanolamide molecules, as well as to decrease in the surface charge density of micelles which in its turn is resulted by the dominant localization of monoethanolamide molecules between $\mathrm{C}_{16} \mathrm{PyCl}$ hydrocarbon chains in the region of polar groups [30]. This effect of changing structure of template micelles is more manifested for reacting systems of $\mathrm{EAC}_{14}$ (Table 1, FMS-3M and FMS-6M, FMS-3H and FMS-6H samples).

As for the molar ratio of templating substances, for it the region which is close to the saturation of micelles with a solubilizate is more preferable. Higher content of solubilizate content results likely in the formation of excessively hard and dense micelles, which weakens the co-organization of reacting system components in the interface into a single spatial structure with framework-forming substance. As a result, this leads to the deterioration of material spatial structure (Table 1, FMS-5 and FMS-6 samples). 

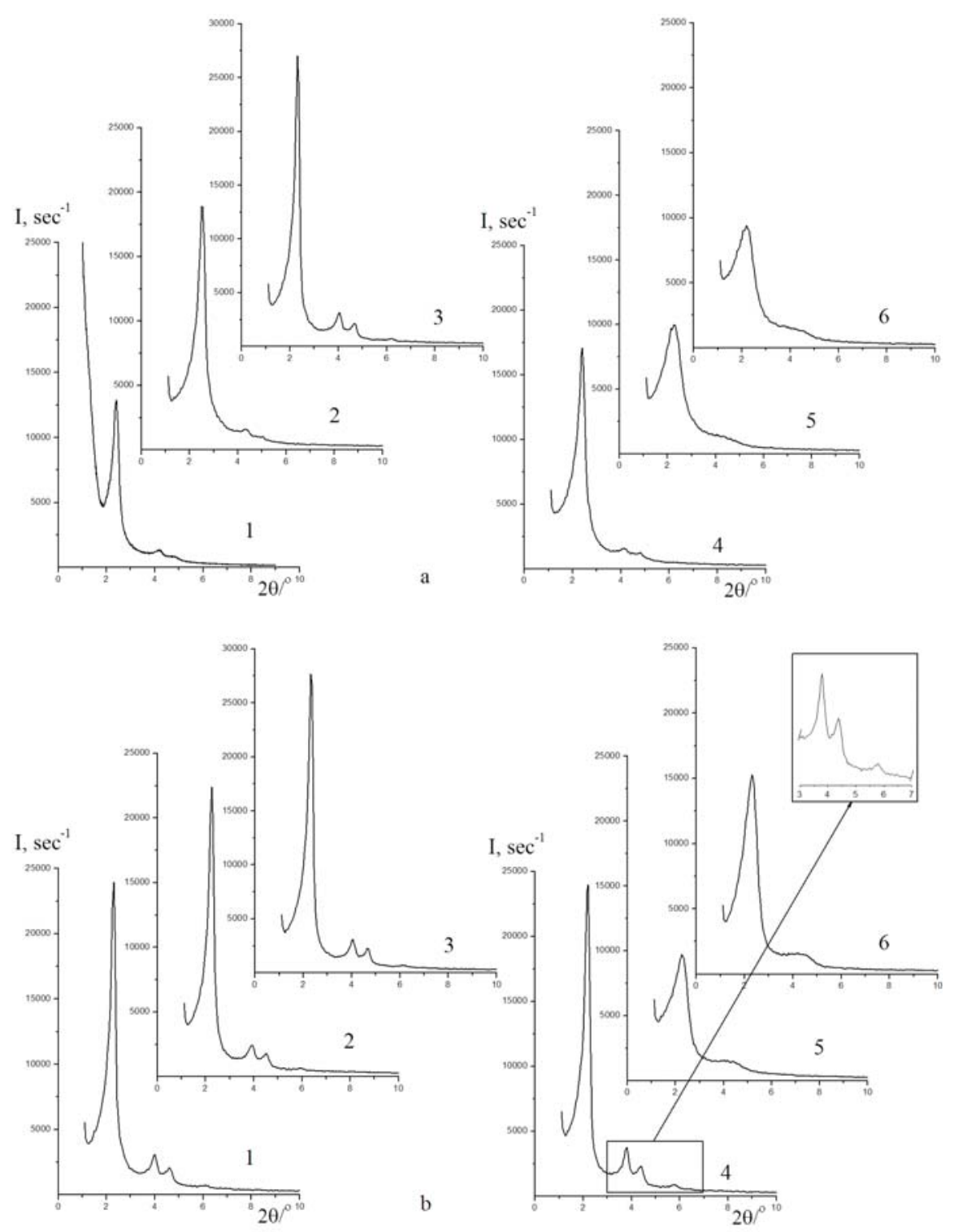

Figure 3. X-ray diffraction patterns of functionalized mesoporous silicas: (a) 1- FMS-1M; 2 - FMS-2M; 3 FMS-5M; 4 - FMS-5.1M; 5 - FMS-5.2M; 6 - FMS-5.2H and (b) 1 - FMS-4M; 2 - FMS-4H; 3 - FMS-6M; 4 - FMS-6H; 5 - FMS-6.1H; 6 - FMS-6.2H.

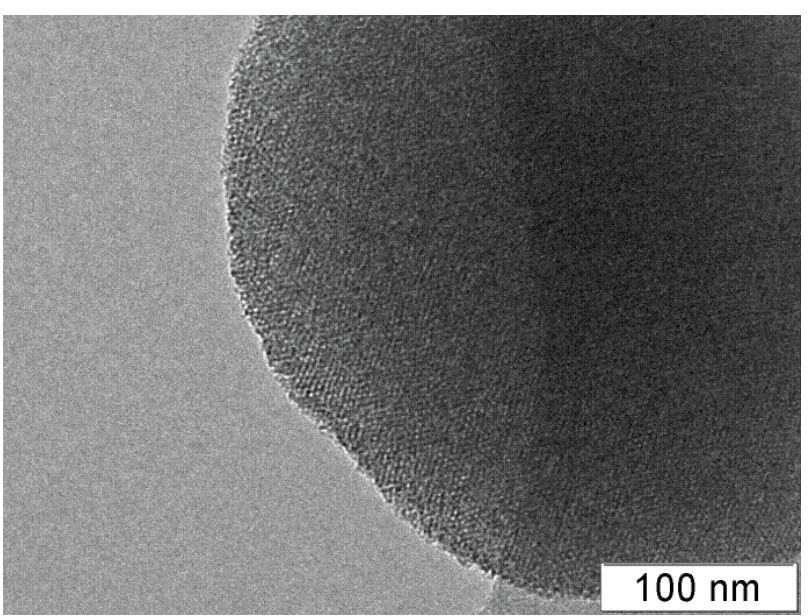

Figure 4. TEM micrograph of FMS-2M sample. 
Fig. 5 shows the nitrogen adsorption-desorption isotherms for the samples which did not contain template. All of them have S-like bend in the region of relative pressures $0.1-0.4$. They may be ascribed to type IV under the IUPAC classification [31].

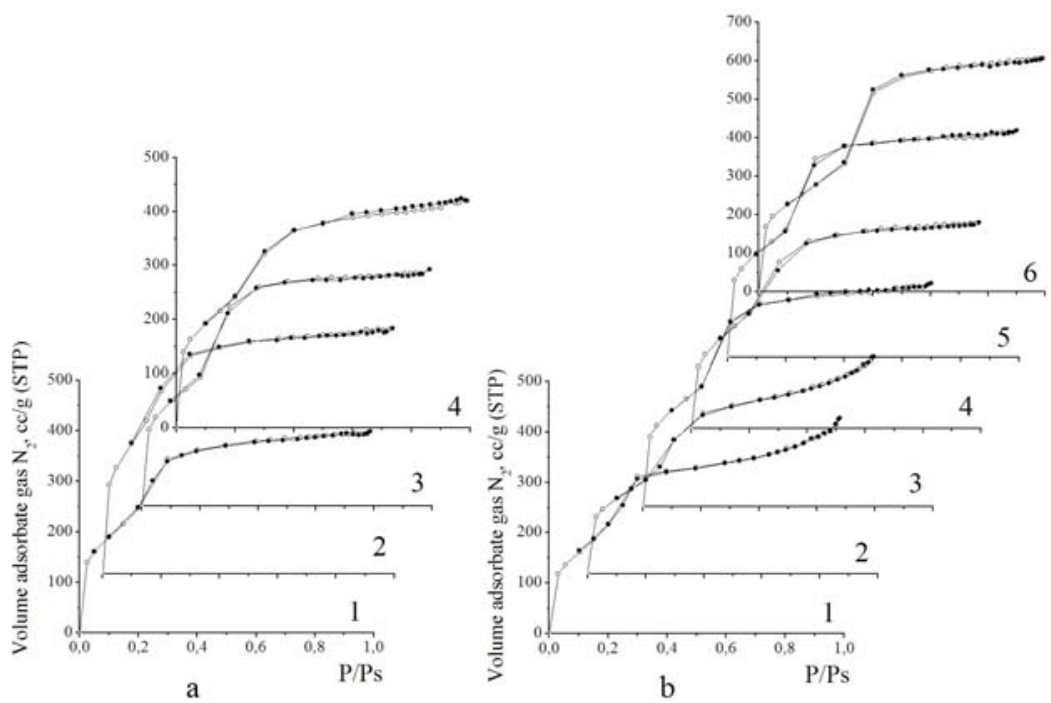

Figure 5. Isotherms of nitrogen adsorption $(\circ)$ - desorption( $\bullet$ ) of synthesized mesoporous samples: (a) 1FMS-1M; 2 FMS-2M; 3 - FMS-5M; 4 - FMS-5.2M and (b) 1 - FMS-3M; 2 - FMS-3H; 3 - FMS-4M;

\section{4 - FMS-4H; 5 FMS-6M; 6 - FMS-6H.}

However, the hysteresis loop is not presented on these isotherms. The Table 1 presents parameters of the porous structure of synthesized samples which were calculated by usage of the obtained isotherms. This table also shows that the effect from introduction of the second template agent $\left(\mathrm{EAC}_{\mathrm{m}}\right)$ is of different character and is determined by the length of its carbon chain. Thus, in the case of $\mathrm{EAC}_{12}$ the change of porous structure parameters is not observed practically (cf. FMS-5M and FMS-3M samples in Table 1). However, in the case of $\mathrm{EAC}_{14}$ the increase of practically all the parameters of porous structure is observed (cf. FMS-6M and FMS-3M samples in Table 1). In last case the same effect is observed by replacing mother liquor for water at HTT of mesophases (cf. FMS-6H and FMS-3H samples in Table 1). Therefore, the formation of more ordering spatial structure conduces to the increase of structural-adsorption characteristics of material as well. At the same time it is obvious that the rising concentration just of the second templating agent $\mathrm{EAC}_{\mathrm{m}}$ in the reacting solution (Table 1, FMS-5.1M sample) or rising of its concentration with alkoxysilane concentration results as a rule in the formation of less ordered structure (Fig. 3).

Hence, this paper shows that the use of bitemplate solubilization composition which is based on micelle-forming surfactant $\left(\mathrm{C}_{16} \mathrm{PyCl}\right)$ and non-micelle-forming surfactant (monoethanolamides of saturated $n$-aliphatic acid $\left(\mathrm{EAC}_{12.14}\right)$ ) improves structural and structural-adsorption characteristics of resulting functionalized material. Among the studied systems the most effective one is bitemplate solubilization composition $\mathrm{EAC}_{14} / \mathrm{C}_{16} \mathrm{PyCl}$ with the molar ratio of $0.05 / 1$. It may be forecasted that this effect will be observed for other variants of the bitemplate synthesis of functionalized mesoporous silicas as well.

\section{Acknowledgement}

The authors are thankful to NATO Science for Peace Programme (grant 978006) for partial funding of this work.

\section{References}

[1]. Chuiko, A. A. (ed) Chemistry of Silica Surface; Institute of Surface Chemistry: Kyiv, 2001 (in Russ.).

[2]. Zaitsev,V. N. Complexing Silicas: Synthesis, Structure of Bonded Layer and Surface Chemistry; Folio, Khar'kov, 1997 (in Russ.). Kholin, Yu. V.; Zaitsev, V. N. Complexes on a Surface of Chemically Modified Silicas; Folio, Khar'kov, 1997 (in Russ.).

[3]. Vansant, E. F.; Voort Van Der P.; Vrancken, K. C. Characterization and Chemical Modification of the Silica Surface; Elsevier: Amsterdam, 1995.

[4]. Tertykh, V. A.; Belyakova, L. A. Chemical Reactions with Participation of Silica Surface; Naukova Dumka: Kyiv, 1991 (in Russ.).

[5]. Lisichkin, G. V. (ed) Chemistry of Grafting Surface Compounds; Fizmatlit: Moscow, 2003 (in Russ.).

[6]. Sadasivan, S.; Khushalani, D.; Mann, S. J. Mater. Chem. 2003, 13, 1023.

[7]. Macquarrie, D. J.; Jackson, D. B. et al J. Mater. Chem. 2001, 11, 1843. 
[8]. Mel'nyk, I. V.; Zub, Yu. L. et al in: Sayari, A. and Jaroniec, M. (eds) Nanoporous Materials III. Elsevier: Amsterdam, 2002.

[9]. Stein, A.; Melde, B. J. et al Adv. Mater. 2000, 12, 1403.

[10]. Mercier, L.; Pinnavaia, T. J. Chem. Mater. 2000, 12, 188.

[11]. Hall, S. R.; Fowler, C. E. et al Chem Commun (1999) 201.

[12]. Macquarrie, D. J. Chem. Commun. 1996, 1961.

[13]. Fowler, C. E.; Burkett, S. L.; Mann, S. Chem. Commun. 1997, 1769.

[14]. Burkett, S. L.; Sims, S. D.; Mann, S. Chem. Commun. 1996, 1367.

[15]. Margolese, D.; Melero, J. A. et al Chem. Mater. 2000, 12, 2448.

[16]. Corriu, R. J. P.; Datas, L. et al Chem, Commun. 2001, 763.

[17]. Van Rhijn, W. V.; De Vos, D. E. et al Chem. Commun. 1998, 317.

[18]. Elings, J. A.; Ait-Meddour, R. et al Chem. Commun. 1998, 2707.

[19]. Yaroshenko, N. A.; Shvets, A. V. et al Colloid. J. 2003, 65, 563 (in Russ.).

[20]. Melnyk, I. V.; Gona, O. I. et al in: Innocenzi, P.; Zub, Yu. L.; Kessler, V. G. (eds), Sol-Gel Methods for Materials Processing (ARW NATO). Springer: Dordrecht. 2008.

[21]. Sanders, H. L.; Nassau, M. Soap Chem Specialties. 1960, 36, 122.

[22]. Zub, Yu. L.; Melnyk, I. V. et al Chemistry, Physics and Technology of Surface, 2002, 7, 35.

[23]. Brunauer, J. S.; Emmet, P. H.; Teller, E. J. J. Am. Chem. Soc. 1938, 60, 309.

[24]. Barret, E. P.; Joyner, L. G.; Halenda, P. P. J. Am. Chem. Soc. 1951, 73, 373.

[25]. Beck, J. S.; Vartuli, J. C. et al J. Am. Chem. Soc. 1992, 114, 10834.

[26]. Yaroshenko, N. A.; Ilin, V. G. J. Appl. Chem. 2004, 77, 1787 (in Russ.).

[27]. Finn, P. L.; Sliniakova, I. B. Colloid. J. 1975, 37, 723 (in Russ.).

[28]. Jensen, K. A.; Nielsen, P. H. Acta. Chem. Scand. 1966, 20, 597.

[29]. Gona, O. I.; Zub, Yu. L. et al J. Phys. Chem. 2007, 81, 399 (in Russ.).

[30]. Hoshino, T.; Imamura, Y. Bull. Chem. Soc. Jap. 1990, 63, 502.

[31]. Sing, K. S. W.; Everett, D. H. et al Pure. Appl. Chem. 1985, 57, 603. 